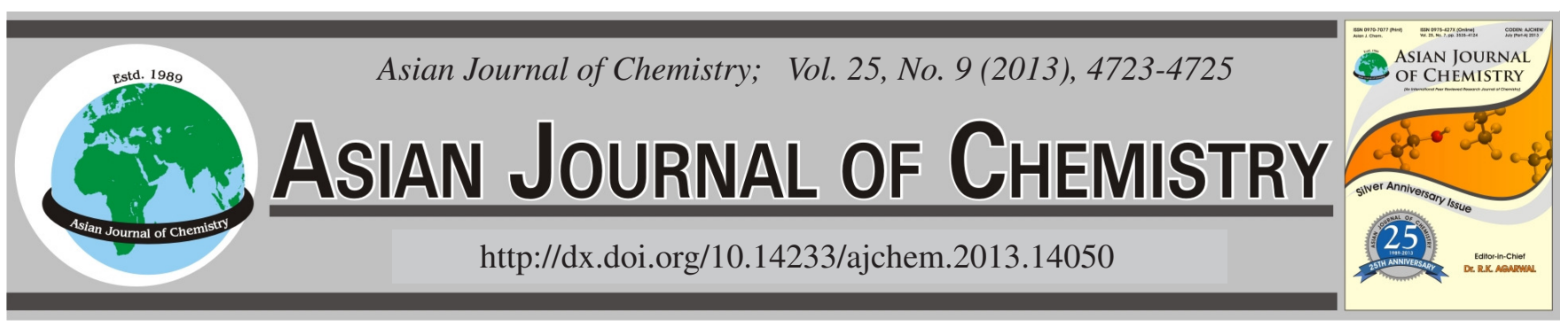

\title{
Structure-Antioxidant Activity Relationship of Some Flavonoids Isolated from Warionia saharae (Asteraceae)
}

\author{
Mebarka Belboukhari ${ }^{1,2,2}$, Abdelkrim Cheriti $^{1}$ and Nasser Belboukhari ${ }^{2, *}$
}

${ }^{1}$ Phytochemistry and Organic Synthesis Laboratory, University of Bechar, Bechar, 08000, Algeria

${ }^{2}$ Bioactive Molecule and Chiral Separation Laboratory, University of Bechar, Bechar, 08000, Algeria

*Corresponding author: E-mail: nasro14@maktoob.com; belboukhari.nasser@yahoo.com

(Received: 11 May 2012;

Accepted: 4 March 2013)

AJC-13057

The antioxidant behaviour of flavonoids including flavone, flavanol and isoflavone isolated from leaves of Warionia saharae and the
related activity-structure relationships were investigated by measuring their abilty to scavenge the free radical 2,2-diphenylpicrylhydrazyl
show that the antioxidant activity depends both on substitution of hydroxyl groups of the flavonoids skeleton and the presence of an
unsaturation at the C2 -C 3 bond in conjugation with 4 oxo function.
Key Words: Flavonoid, Warionia saharae, Antioxidant, Free radical, Scavenge.

\section{INTRODUCTION}

Reactive oxygen species readily attack and induce oxidative damage to various biomolecules including proteins, lipids, lipoproteins and DNA. This oxidative damage is a crucial etiological factor implicated in several chronic human diseases namely cardiovascular diseases, rheumatism, diabetes mellitus and cancer ${ }^{1,2}$.

The human body possesses many defense mechanisms against oxidative stress, including antioxidant enzyme and nonenzymatic compounds ${ }^{3}$, antioxidants are chemical substances that reduce or prevent oxidation, they have the ability to counteract the damaging effects of free radicals in tissues ${ }^{1,4}$.

Many studies have shown that phenolic compounds display antioxidant activity as a result of their capacity to scavenge free radicals. Flavonoids belong to a group of phenolic compound with a number of biological activities such as antibacterial,antimutagenic, cytotoxic, anticarcinogenic and antioxidant activity ${ }^{5}$.

The antioxidant property of flavonoids was the first mechanisms of action studied in particular with regard to their protective effect against cardiovascular diseases, flavonoids have been shown to be highly effective scavengers of most types of oxidizing molecules, including singlet oxygen and various free radicals ${ }^{6,7}$.

The objective of this study was to elucidate the antioxidant activity of flavonoids isolated from leaves of Warionia saharae and determine their activity-structure relationships as antioxidant by using the DPPH radical scavenging.

\section{EXPERIMENTAL}

DPPH radical scavenging method: The antioxidant activity of the flavonoids isolated from leaves of Warionia saharae was assesses by the mean of 2,2-diphenyl-1picrylhydrazyl (DPPH) colorimetric method ${ }^{1}$. This method depends on the reduction of purple DPPH to a yellow coloured diphenylpicrylhydrazine and the remaining $\mathrm{DPPH}^{\text {, which }}$ showed maximum absorption at $517 \mathrm{~nm}$ was measured (spectrophotometer). About $2 \mathrm{~mL}$ of a $20 \mathrm{mg} / \mathrm{mL}$ DPPH solution were added to $1 \mathrm{~mL}$ of a methanolic solution of each fractions $(1-100 \mu \mathrm{g} / \mathrm{mL})$. A mixture of $2 \mathrm{~mL}$ of DPPH and $1 \mathrm{~mL}$ of methanol served as control. The mixture was shaken vigorously then incubated for $15 \mathrm{~min}$ in darkness at room temperature. Absorbance was measured at $517 \mathrm{~nm}$, each experiment was performed in triplicate. The DPPH radical scavenging activity was calculated according to the following equation:

$$
\text { DPPH radical scavenging activity }(\%) \frac{\mathrm{A}_{\text {control }}-\mathrm{A}_{\text {sample }}}{\mathrm{A}_{\text {control }}}
$$

where $\mathrm{A}_{\text {sample }}$ : absorbance of sample; $\mathrm{A}_{\text {control }}$ : absorbance of control.

\section{RESULTS AND DISCUSSION}

Ten different flavonoids including flavones, flavanol and isoflavone isolated from leaves of Warionia saharae were measured for antioxidant properties in this study by using DPPH radical scavenging. 
TABLE-1

STRUCTURE AND ANTIOXIDANT ACTIVITY OF TESTED FLAVONE

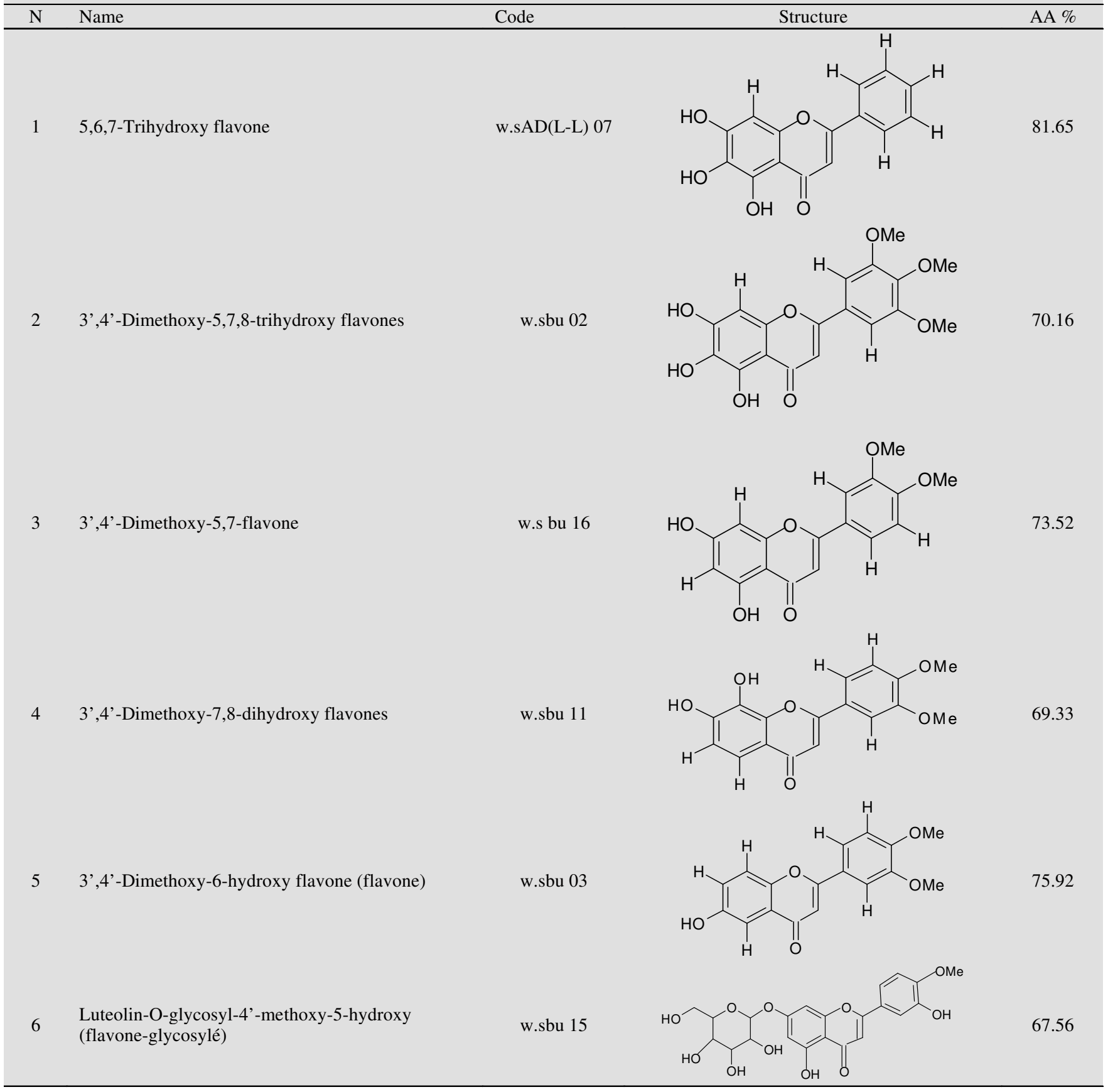

As shown in Table-1, the 5,7 hydroxyl group in A ring the C2-C3 double bond in conjugation with 4 oxo $^{8-10}$ function present in compound $\mathbf{1}$ (5,6,7-trihydroxy flavones), is known to improve antioxidant efficiency and this may be the reason why this flavone has a high potent antioxidant activity $(86.65 \%)$.

As present in Table-1, it is observed that compounds 2, 3, 4 having a lower antioxidant activity than the activity of compound 1 due to presence of methoxylation group in $3^{\prime}, 4^{\prime}$ and 5 ' position in A ring ${ }^{9,10}$.

The presence of glycosylation group in 7 position for compound 6 reduce the antioxidant activity ${ }^{10}$.

In the Table-2, the antioxidant activity of taxifolin 6hydroxy is higher $96.40 \%$ due to existence of hydroxyl group in 5,7 position in A ring and 3 position in $\mathrm{C} \mathrm{ring}^{8-10}$.
The taxifolin 6-hydroxy, 4' methoxy has a low antioxidant activity percentage than taxifolin 6-hydroxy due to presence of methoxylation group in $5^{\prime}$ position in $\mathrm{A}$ ring ${ }^{10}$.

As present in Table-3, the compound $\mathbf{1}$ has a high antioxidant activity $86.71 \%$ due to presence of hydroxyl group in $5,6,7$ position in A ring and the unsaturation between $\mathrm{C} 2-\mathrm{C} 3$ in conjugation with 4-oxo function in $\mathrm{C}$ ing $^{8-12}$.

The absence of unsaturation between $\mathrm{C} 2-\mathrm{C} 3$ in $\mathrm{C}$ ring reduce the antioxidant activity for compound $2^{9,11-13}$.

\section{Conclusion}

The results of this study provide evidence that flavonoids have radical scavenging activity or antioxidant activity due to presence of substitution patterns on the B ring appear to be the most important contributor to the antioxidant activity, 


\begin{tabular}{cccc}
\multicolumn{2}{c}{ STRUCTURE AND ANTIOXIDANT ACTIVITY OF TESTED FLAVANOLS } \\
\hline $\mathrm{N} \quad$ Taxifolin 6-hydroxy (flavanol)
\end{tabular}

6-Hydroxy biochanin A (isoflavone)

hydroxyl groups boost the antioxidant activity, whereas methoxy and glycosyl groups reduce the antioxidant activity. Presence of unsaturation between $\mathrm{C} 2-\mathrm{C} 3$ in conjugation with 4 oxo function enhances the antioxidant capacity. A hydroxyl group at the $\mathrm{C} 3$ position is also beneficial to the ability of flavonoids to scavenge free radical.

\section{REFERENCES}

1. R.B. Ammar, W. Bhouri, M.B. Sghaier, J. Boubaker, I. Skandrani, A. Neffati, I. Bouhlel, S. Kilani, A.-M. Mariotte, L. Chekir-Ghedira, M.G. Dijoux-Franca and K. Ghedira, Food Chem., 116, 258 (2009).

2. K. Pong, Expert Opinion Biol. Ther, 3, 127 (2003).

3. E.S. Abdel-Hameed, Food Chem., 114, 1271 (2009).

4. M. Bandyopadhya, R. Chakraborty and U. Raychaudhui, LWT-Food Sci. Technol., 40, 842 (2007).
5. B. Modak, M.L. Contreras, F. González-Nilo and R. Torres, Bioorg. Med. Chem. Lett., 15, 309 (2005).

6. P. Montoro, A. Braca, C. Pizza and N. De Tommasi, Food Chem., 92, 349 (2005)

7. L. Bravo, Nutr. Rev., 56, 317 (1998).

8. M. Belboukhari, A. Cheriti and N. Belboukhari, Nat. Prod., 7, 150 (2011).

9. C.A. Rice-Evans, N. Miller and G. Paganga, Trends Plant Sci., 2, 152 (1997).

10. C.A. Rice-Evans, N.J. Miller and G. Paganga, Free Radic. Biol. Med., 20, 933 (1996).

11. K.E. Heim, A.R. Tagliaferro and D.J. Bobilya, J. Nutr. Biochem., 13, 572 (2002).

12. A. Arora, M.G. Nair and G.M. Strasburg, Free Radic Biol. Med., 24, 1355 (1998).

13. G. Cao, E. Sofic and R.L. Prior, Free Radic Biol. Med., 22, 749 (1997). 